\title{
Association of intraoperative hyperglycemia and postoperative outcomes in patients undergoing non-cardiac surgery: a multicenter retrospective study
}

\author{
Nirav J. Shah ${ }^{1 *}$ D, Aleda Leis ${ }^{1}$, Sachin Kheterpal ${ }^{1}$, Michael J. Englesbe ${ }^{2}$ and Sathish S. Kumar ${ }^{1}$
}

\begin{abstract}
Background: While pre and postoperative hyperglycemia is associated with increased risk of surgical site infection, myocardial infarction, stroke and risk of death, there are no multicenter data regarding the association of intraoperative blood glucose levels and outcomes for the non-cardiac surgical population.

Methods: We conducted a retrospective cohort study from the Michigan Surgical Quality Collaborative, a network of 64 hospitals that prospectively collects validated data on surgical patients for the purpose of quality improvement. We included data for adult general, vascular, endocrine, hepatobiliary, and gastrointestinal operations between 2013 and 2015. We assessed the risk-adjusted, independent relationship between intraoperative hyperglycemia (glucose $>180$ ) and the primary outcome of 30-day morbidity/mortality and secondary outcome of infectious complications using multivariable logistic regression modelling. Post hoc sensitivity analysis to assess the association between blood glucose values $\geq 250 \mathrm{mg} / \mathrm{dL}$ and outcomes was also performed.

Results: Ninety-two thousand seven hundred fifty-one patients underwent surgery between 2013 and 2015 and 5014 (5.4\%) had glucose testing intra-operatively. Of these patients, 1647 patients (32.9\%) experienced the primary outcome, and 909 (18.1\%) the secondary outcome. After controlling for patient comorbidities and surgical factors, peak intraoperative glucose $>180 \mathrm{mg} / \mathrm{dL}$ was not an independent predictor of 30-day mortality/morbidity (adjusted OR 1.05, 95\%Cl:0.86 to 1.28; $p$-value 0.623; model c-statistic of 0.720 ) or 30-day infectious complications (adjusted OR 0.93, 95\%Cl:0.74,1.16; p 0.502; model c-statistic of 0.709). Subgroup analysis for patients with or without diabetes yielded similar results. Sensitivity analysis demonstrated blood glucose of $250 \mathrm{mg} / \mathrm{dL}$ was a predictor of 30-day mortality/morbidity (adjusted OR: 1.59, 95\% Cl: 1.24, 2.05; $p<0.001$ ).

Conclusions: Among more than 5000 patients across 64 hospitals who had glucose measurements during surgery, there was no difference in postoperative outcomes between patients who had intraoperative glucose $>180 \mathrm{mg} / \mathrm{dL}$ compared to patients with glucose values $\leq 180 \mathrm{mg} / \mathrm{dL}$.
\end{abstract}

Keywords: Hyperglycemia, Complications, Anesthesiology

\footnotetext{
* Correspondence: nirshah@med.umich.edu

'Department of Anesthesiology, University of Michigan Medical School, $\mathrm{H} 247$

UH, SPC 5048, 1500 East Medical Center Drive, Ann Arbor, MI 48109-5048,

USA

Full list of author information is available at the end of the article
}

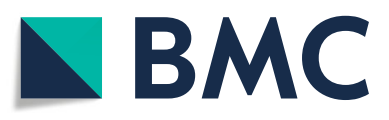

(c) The Author(s). 2020 Open Access This article is licensed under a Creative Commons Attribution 4.0 International License, which permits use, sharing, adaptation, distribution and reproduction in any medium or format, as long as you give appropriate credit to the original author(s) and the source, provide a link to the Creative Commons licence, and indicate if changes were made. The images or other third party material in this article are included in the article's Creative Commons licence, unless indicated otherwise in a credit line to the material. If material is not included in the article's Creative Commons licence and your intended use is not permitted by statutory regulation or exceeds the permitted use, you will need to obtain permission directly from the copyright holder. To view a copy of this licence, visit http://creativecommons.org/licenses/by/4.0/ The Creative Commons Public Domain Dedication waiver (http://creativecommons.org/publicdomain/zero/1.0/) applies to the data made available in this article, unless otherwise stated in a credit line to the data. 


\section{Background}

Patients undergoing surgery may have high glucose values, regardless of whether they have diabetes. Perioperative hyperglycemia has been shown to be associated with increased risk of surgical site infection, myocardial infarction, stroke and risk of death [1-3]. Stress hyperglycemia (hyperglycemia without diagnosis of diabetes) can develop with surgery and critical illness, and is more common during cardiac surgery. Evidence suggests that outcomes for patients with stress hyperglycemia are worse than in patients with hyperglycemia who have diabetes [4-7].

Most of the published literature related to outcomes in patients with intraoperative hyperglycemia has been in the cardiac surgical population, and there is growing evidence on the appropriate treatment of perioperative high glucose levels in this group [8]. Blaha et al. found that adhering to a tight glucose control protocol starting in the intraoperative period, instead of postoperatively, reduced perioperative adverse events, especially for nondiabetics [9].

Other studies have demonstrated associations between perioperative hyperglycemia and post-operative morbidity in the noncardiac surgical population, using data obtained pre- and post-operatively, but these studies do not take intra-operative values into account [10-12]. Despite evidence that high glucose levels need to be addressed in the perioperative setting, there is little data focusing on intraoperative glucose levels and outcomes for the noncardiac surgical population [10]. Small, single center analyses have demonstrated a tenuous relationship between severe hyperglycemia and postoperative infectious complications; however, these data suffer from overfit models or data from more than decade ago [13]. As a result, the association between intraoperative glucose and outcomes remain controversial. While most anesthesiologists would acknowledge that treatment of "high" glucose during surgery may improve postoperative outcomes, they may also worry that symptoms of hypoglycemia are masked by general anesthesia, posing a unique risk to aggressive glycemic management during the intraoperative period. Additionally, there are workflow factors that limit compliance with this important intervention, such as access to point of care glucose measuring devices. However, the use of real-time alerting systems has been shown to modify glucose-checking behavior and improve compliance [14, 15].

The aim of our study was to elucidate the relationship between intraoperative hyperglycemia and postoperative outcomes using a large multicenter registry reflecting small and large community hospitals and academic centers, with a variety of care processes and patient profiles. We hypothesized that intraoperative hyperglycemia (peak glucose $>180 \mathrm{mg} / \mathrm{dL}$ or $10 \mathrm{mmol} / \mathrm{L}$ between the time points anesthesia start and anesthesia end) during noncardiac surgery is an independent predictor of combined 30-day morbidity and mortality after controlling for known patient and procedural risk factors.

\section{Methods}

We conducted a retrospective cohort study from the Michigan Surgical Quality Collaborative (MSQC), a voluntary network of approximately 70 hospitals that collects data on surgical patients for the purpose of quality improvement and research using a foundation of the National Surgical Quality Improvement Program data elements and methodology [16, 17]. The MSQC is funded by Blue Cross Blue Shield of Michigan, a private, not-for-profit insurance company. Although Blue Cross Blue Shield provides financial support for the project, they are not involved in the policy recommendations that are developed within the collaborative. MSQC hospitals are predominantly community hospitals but do include several teaching facilities with surgical and/or medical residents. Patient selection uses an algorithm designed to minimize selection bias. Cases are reviewed using a sampling algorithm designed to minimize selection bias and represent $90 \%$ of eligible cases, approximately 50,000 cases per year [18]. De-identified MSQC data collection for quality improvement is Institutional Review Board exempt; the current study using a limited data set derived from the MSQC database was approved by the University of Michigan Institutional Review Board review (HUM 00091060).

We included data for adult general, vascular, endocrine, hepatobiliary and gastrointestinal (upper and colorectal) cases between 2013 and 2015 and excluded patients with American Society of Anesthesia Classification (ASA) 5 or 6 . Each participating hospital employs at least one trained Surgical Clinical Quality Reviewer to prospectively collect data on surgery patients, their operations, and 30-day outcomes. Patient data collected from the electronic or paper medical record included demographics (age, gender, body mass index (BMI), ASA class, emergent status, surgical procedure group), preoperative comorbidities (diabetes, ventilator dependence, chronic obstructive pulmonary disease (COPD), pneumonia, ascites, congestive heart failure, hypertension, history of peripheral vascular disease, currently requiring or on dialysis, disseminated cancer, open wound, use of steroids/immunosuppressive medications for chronic condition, $>10 \%$ loss of body weight in the 6 months prior to surgery, alcohol use $>2$ drinks/day in the 2 weeks prior to surgery, presence of sleep apnea, cigarette use within 1 year, presence of sepsis or severe sepsis within $48 \mathrm{~h}$ prior to surgery, history of coronary artery disease, and history of deep vein thrombosis), intraoperative characteristics (surgical time, peak blood glucose 
measurements, insulin administration), and postoperative outcomes (Appendix A). Although the definition of intraoperative hyperglycemia remains controversial, a specific threshold is necessary for a robust, pre-planned primary analysis. We selected a glucose of $180 \mathrm{mg} / \mathrm{dL}$ given that several studies have shown an association between inpatient hyperglycemia (defined as greater than $180 \mathrm{mg} / \mathrm{dL}$ ) and adverse clinical outcomes [10, 12]. This manuscript was drafted adherent to the applicable STROBE guidelines [19].

\section{Outcomes}

The primary outcome was combined 30-day mortality / morbidity including infectious, cardiovascular, thromboembolic, and neurologic adverse events as detailed in Appendix A. The secondary outcome was 30-day infectious complications including surgical site infections, pneumonia, urinary tract infections, sepsis, central line associated bloodstream infections, and Clostridium difficile infection. Each of these complications was prospectively collected by a trained nurse data collector per MSQC definitions and processes [16].

\section{Statistical analysis}

Univariate associations were used to compare demographic and clinical characteristics among patients with a peak glucose $>180 \mathrm{mg} / \mathrm{dL}$ to those with glucose $\leq 180$ $\mathrm{mg} / \mathrm{dL}$, and also with and without history of diabetes in the entire patient cohort and in the cohort of patients who underwent glucose testing (cohort study group). Normality of all continuous data was checked using the Kolmogorov-Smirnov test. Data are presented as frequencies with percentages for categorical variables and medians with 25th and 75th percentiles for continuous variables. Univariate differences were assessed using Chi-square or Fisher's Exact tests for categorical variables and Mann-Whitney U or Kruskal-Wallis tests for continuous variables, as appropriate.

Non-parsimonious multivariable logistic regression models were used for the primary and secondary outcomes to determine if glucose $>180 \mathrm{mg} / \mathrm{dL}$ was an independent predictor of the primary or secondary outcomes. Variables chosen for model inclusion based on clinical significance were: age, gender, race, World Health Organization Body Mass Index classification, ASA class, procedure, urgent/emergent case status, year of case, intraoperative administration of insulin, surgical duration, intraoperative blood glucose $>180 \mathrm{mg} / \mathrm{dL}$, and total number of comorbidities (diabetes, ventilator dependence, COPD, pneumonia, ascites, congestive heart failure, hypertension, history of peripheral vascular disease, currently requiring or on dialysis, disseminated cancer, open wound, use of steroids/immunosuppressive medications for chronic condition, > 10\% loss of body weight in the 6 months prior to surgery, alcohol use $>2$ drinks/day in the 2 weeks prior to surgery, presence of sleep apnea, cigarette use within 1 year, presence of sepsis or severe sepsis within $48 \mathrm{~h}$ prior to surgery, history of coronary artery disease, and history of deep vein thrombosis). Before any models were constructed, covariates were assessed for collinearity using a Pearson's correlation matrix. Pairs of variables with a correlation $>0.70$ were deemed to be collinear, and the variable with the larger univariate effect size was kept in the model. All other variables were entered into the model. Any covariate deemed to be statistically significant in the model after adjusting for all other variables was considered to be an independent predictor of the outcome.

We performed a pre-planned sensitivity analysis to assess the impact of a tight glucose threshold by using glucose $>150 \mathrm{mg} / \mathrm{dL}$ as the independent predictor with the same multivariable logistic regression model. A glucose of $150 \mathrm{mg} / \mathrm{dL}$ was used for the sensitivity analysis as several previous studies have used this threshold to define strict control [20,21]. In addition, we performed the following pre-planned subgroup analyses: elective cases, non-diabetic cases, inpatient/admit patients, and surgical duration greater than or equal to $60 \mathrm{~min}$ with glucose $>$ $180 \mathrm{mg} / \mathrm{dL}$ as the independent predictor. A post hoc sensitivity analysis to assess the association between blood glucose values $\geq 250 \mathrm{mg} / \mathrm{dL}$ and outcomes was performed in response to reviewer requests. If missing, surgical times were imputed as the median time (represented by the other cases in the database) for the primary surgical CPT. Missing BMI were also imputed.

A $p$-value of $<0.05$ was considered statistically significant for all analyses. Measures of effect size for all logistic regression models were reported as adjusted odds ratio and 95\% confidence intervals for all model covariates. All analysis was conducted using SAS version 9.4 (SAS Institute, Cary, NC) and SPSS version 24 (IBM).

\section{Results}

Of the 92,751 patients who underwent general, hepatobiliary, gastrointestinal (GI), vascular, and endocrine surgery from 2013 to 2015, the study cohort consisted of 5014 patients $(5.4 \%)$ who had intraoperative glucose testing performed (Fig. 1). Patients with blood glucose testing had significantly more comorbidities (except for alcohol and tobacco use), were older, had longer surgeries, and worse outcomes than those who did not receive glucose testing (Table 1). In the full study population, 18,191 out of 92,751 patients (19.6\%) had a history of diabetes.

Of the glucose testing cohort, 1647 patients $(32.9 \%)$ experienced the primary outcome of 30-day morbidity/ mortality, and 909 (18.1\%) the secondary outcome of 30day infectious complications. Of the glucose testing cohort, 1414 patients $(28.2 \%)$ had a glucose $>180 \mathrm{mg} / \mathrm{dL}$ 


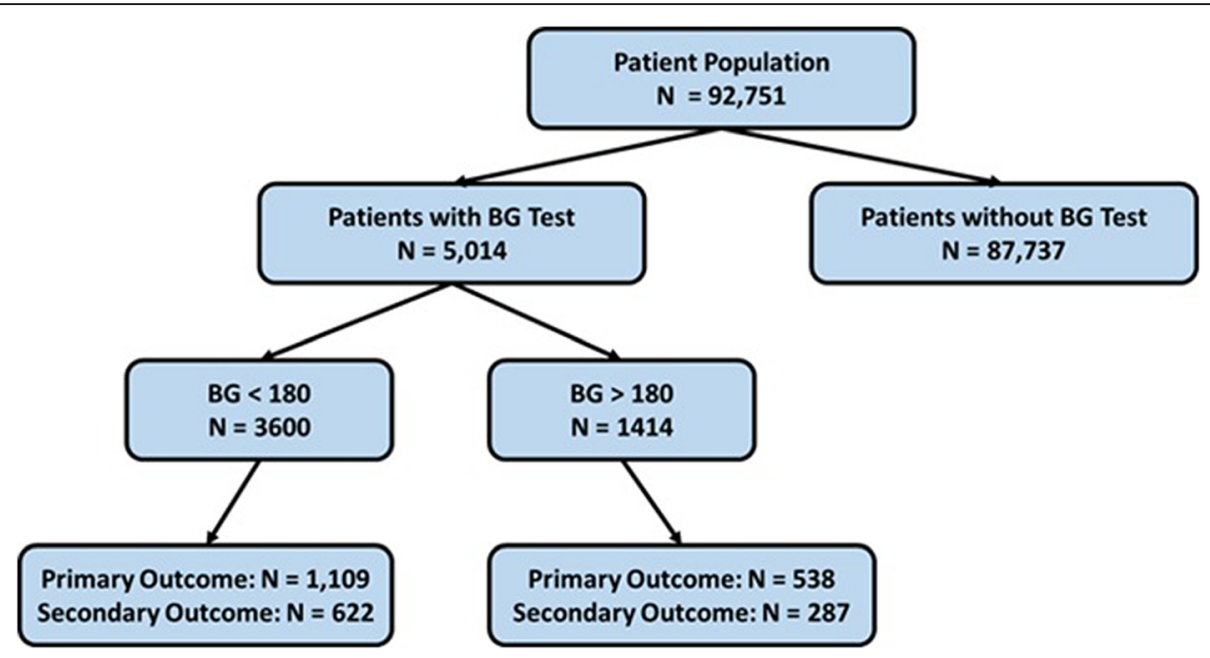

Fig. 1 Patient Population Flowchart

(Table 2). These patients were more likely to have diabetes $(76.4 \%$ vs. $59.8 \%, p<0.001)$, hypertension $(79.4 \%$ vs. $75.2 \%, p=0.002)$, obesity ( $56.1 \%$ vs. $45.7 \%, \mathrm{p}<0.001)$, and intraoperative insulin administration $(55.7 \%$ vs. $6.6 \%, \mathrm{p}<0.001)$. Those with a glucose $>180 \mathrm{mg} / \mathrm{dL}$ were less likely to have coronary artery diease (CAD) $(32.0 \%$ vs. $35.3 \%, p=0.026)$ and were of slightly younger age (median 65.0 vs. 66.0, $p=0.003$ ). Unadjusted infectious complication rates and 30-day morbidity and mortality rates were significantly higher in the glucose $>180 \mathrm{mg} /$ dL group (20.3\% vs. $17.3 \%, p=0.013 ; 38.1 \%$ vs. $30.9 \%$, $p<0.001$ ).

There was no significant collinearity between the model variables, so all were included. After adjusting for the model covariates, there was no statistically significant difference in the odds of 30-day combined morbidity and mortality between those with a glucose $>180$ $\mathrm{mg} / \mathrm{dL}$ compared to those with a glucose $\leq 180 \mathrm{mg} / \mathrm{dL}$ (adjusted OR 1.1, 95\% CI: 0.9, 1.3; $p=0.623$; Table 3). This model had a c-statistic of 0.720 . The same was true for the outcome of infectious complications (adjusted OR 0.90, 95\% CI: 0.70, 1.2; $p=0.502$; model c-statistic of 0.709 ; Table 3 ). A subgroup analysis of only those without diabetes revealed the same absence of statistical significance for both the primary outcome (AOR 0.9, 95\% CI: $0.6,1.3 ; p=0.544$ ) and secondary outcome (AOR 0.8 , 95\% CI: $0.5,1.2 ; p=0.207$ ). Similar results were found for both outcomes in the subgroup analyses for elective cases, admit status cases, inpatient status cases, diabetic only cases, non-diabetic only cases, and surgery duration longer than $60 \mathrm{~min}$. Finally, the sensitivity analysis for a glucose $>150 \mathrm{mg} / \mathrm{dL}$ confirmed the absence of statistically or clinically significant relationship with the primary outcome (AOR 1.1, 95\% CI: 0.9, 1.3; $p=0.287$ ) and secondary outcome (AOR 1.0, 95\% CI: 0.8, 1.2; $p=$ 0.997). Results from our post hoc sensitivity analysis revealed a small statistically significant increase in the odds of 30-day postop morbidity and mortality for every $20 \mathrm{mg} / \mathrm{dl}$ increase in maximum blood glucose over 180 (AOR 1.08, 95\% CI: 1.04, 1.12; $p<0.001$ ) after adjusting for the other specified model covariates. There was no statistically significant increase in the odds of infectious complications for every $20 \mathrm{mg} / \mathrm{dl}$ increase in maximum blood glucose over 180 (AOR 1.01, 95\% CI: 0.97, 1.06; $p=0.646$ ) after adjusting for the other specified model covariates. In the post-hoc sensitivity analysis evaluating a hyperglycemia threshold of blood glucose $\geq 250 \mathrm{mg} / \mathrm{dL}$, these patients had 1.59 times the odds of having 30-day morbidity and mortality than those with a peak intraoperative blood glucose $<250 \mathrm{mg} / \mathrm{dL}$ (adjusted odds ratio: 1.59, 95\% CI: $1.24,2.05 ; p<0.001$ ), but did not have a statistically significantly higher odds of 30-day infectious complications (adjusted odds ratio: 1.14, 95\% CI: 0.85, $1.52 ; p=0.386)$.

\section{Discussion}

The results from this study of surgical registry patients with glucose measurements performed intraoperatively demonstrate no statistically significant difference between patients who had intraoperative glucose $>180 \mathrm{mg} / \mathrm{dL}$ versus those $\leq 180 \mathrm{mg} / \mathrm{dL}$ regardless of diabetes status. There are no published multicenter data evaluating intraoperative glucose data across a large and generalizable population. The SCOAP-CERTAIN study demonstrated that hyperglycemic patients without diabetes had higher rates of complications than patients with diabetes. This study had a similar patient population but could not evaluate intraoperative glucose data [10]. 
Table 1 Demographics and clinical characteristics for full patient population

\begin{tabular}{|c|c|c|c|}
\hline & $\begin{array}{l}\text { Blood Glucose Recorded Intraop } \\
(N=5014) n(\%)\end{array}$ & $\begin{array}{l}\text { Blood Glucose Not Recorded Intraop } \\
(N=87,737) n(\%)\end{array}$ & $P$-value \\
\hline \multicolumn{4}{|l|}{ Patient Demographics } \\
\hline Age & $66.0[57.0$ to 74.0$]$ & $56.0[42.0$ to 68.0$]$ & $<0.001$ \\
\hline WHO BMI Classification & & & $<0.001$ \\
\hline Underweight & $102(2.0)$ & $1717(2.0)$ & \\
\hline Normal & $1056(21.1)$ & $20,849(23.8)$ & \\
\hline Overweight & $1429(28.5)$ & $26,636(30.4)$ & \\
\hline Obese & $2427(48.4)$ & 38,535 (43.9) & \\
\hline ASA Class 3 or 4 & 4449 (88.7) & $42,175(48.1)$ & $<0.001$ \\
\hline Urgent/Emergent Case & $1874(37.4)$ & $35,180(40.1)$ & $<0.001$ \\
\hline Surgical Procedure Group & & & $<0.001$ \\
\hline General & $740(14.8)$ & $19,585(22.3)$ & \\
\hline Endocrine & $410(8.2)$ & $4776(5.4)$ & \\
\hline Hepatobiliary & $560(11.2)$ & $25,816(29.4)$ & \\
\hline Gl (Upper and Colorectal) & $1640(32.7)$ & $28,374(32.3)$ & \\
\hline Vascular & $1664(33.2)$ & $9186(10.5)$ & \\
\hline \multicolumn{4}{|l|}{ Pre-operative Clinical Characteristics } \\
\hline Pre-op Sepsis & & & $<0.001$ \\
\hline None & $4560(91.0)$ & $81,197(92.6)$ & \\
\hline Sepsis & $232(4.6)$ & $4944(5.6)$ & \\
\hline Severe Sepsis & $222(4.4)$ & $1596(1.8)$ & \\
\hline Diabetes & $3231(64.4)$ & $14,976(17.1)$ & $<0.001$ \\
\hline Sleep Apnea & $1061(21.2)$ & $10,576(12.1)$ & $<0.001$ \\
\hline Cancer & $212(4.2)$ & $1199(1.4)$ & $<0.001$ \\
\hline $\mathrm{CHF}$ & $112(2.2)$ & $706(0.8)$ & $<0.001$ \\
\hline COPD & $790(15.8)$ & $8001(9.1)$ & $<0.001$ \\
\hline CAD & $1722(34.3)$ & $13,725(15.6)$ & $<0.001$ \\
\hline $\mathrm{DVT} / \mathrm{PE}^{\mathrm{a}}$ & $542(11.3)$ & $4656(5.8)$ & $<0.001$ \\
\hline $\mathrm{ETOH}>2$ drinks/day in the 2 weeks prior to admission & $145(2.9)$ & $2727(3.1)$ & 0.390 \\
\hline Tobacco use within 1 year - cigarette & $1367(27.3)$ & $23,091(26.3)$ & 0.140 \\
\hline Hypertension & $3831(76.4)$ & $41,833(47.7)$ & $<0.001$ \\
\hline Pneumonia & $80(1.6)$ & $493(0.6)$ & $<0.001$ \\
\hline $\mathrm{HbA} 1 \mathrm{c}^{\mathrm{a}}$ & $7.2[6.3$ to 8.7$]$ & $6.1[5.6$ to 7.2$]$ & $<0.001$ \\
\hline Creatinine $^{a}$ & $0.9[0.7$ to 1.3$]$ & $0.8[0.7$ to 1.0$]$ & $<0.001$ \\
\hline Ascites & $98(2.0)$ & $736(0.8)$ & $<0.001$ \\
\hline $10 \%$ Loss of Body Weight 6 Months Before Surgery & $203(4.1)$ & $1409(1.6)$ & $<0.001$ \\
\hline Steroids/Immunosuppressive Meds for chronic condition & $304(6.1)$ & $2973(3.4)$ & $<0.001$ \\
\hline Currently Requires or is on Dialysis & $223(4.5)$ & $1170(1.3)$ & $<0.001$ \\
\hline Open Wound With or Without Infection & $657(13.1)$ & $3637(4.2)$ & $<0.001$ \\
\hline Peripheral Vascular Disease & 1169 (23.3) & $7119(8.1)$ & $<0.001$ \\
\hline Ventilator Dependent & $96(1.9)$ & $374(0.4)$ & $<0.001$ \\
\hline \multicolumn{4}{|l|}{ Intraoperative Characteristics } \\
\hline Surgical Time (Minutes) & $157.0[98.0$ to 251.0$]$ & $72.0[45.0$ to 116.0$]$ & $<0.001$ \\
\hline \multicolumn{4}{|l|}{ Outcomes } \\
\hline 30 Day Morbidity and Mortality ${ }^{\mathrm{a}}$ & $1647(32.9)$ & $10,341(11.8)$ & $<0.001$ \\
\hline Infectious Complications & $909(18.1)$ & $5874(6.7)$ & $<0.001$ \\
\hline
\end{tabular}


Table 2 Univariate comparison of demographics and clinical characteristics for study cohort

\begin{tabular}{|c|c|c|c|}
\hline & Blood Glucose $<=180(N=3600) n(\%)$ & Blood Glucose > $180(N=1414) n(\%)$ & $P$-value \\
\hline \multicolumn{4}{|l|}{ Patient Demographics } \\
\hline Age & $66.0[57.0$ to 74.0$]$ & $65.0[56.0$ to 72.0$]$ & 0.003 \\
\hline WHO BMI Classification & & & $<0.001$ \\
\hline Underweight & $75(2.1)$ & $23(1.6)$ & \\
\hline Normal & $818(22.7)$ & $232(16.4)$ & \\
\hline Overweight & $1063(29.5)$ & $366(25.9)$ & \\
\hline Obese & $1644(45.7)$ & $793(56.1)$ & \\
\hline Female Gender & $1628(45.2)$ & $677(47.9)$ & 0.090 \\
\hline ASA Class 3 or 4 & $3184(88.4)$ & $1265(89.5)$ & 0.305 \\
\hline Urgent/Emergent Case & $1334(37.1)$ & $540(38.2)$ & 0.455 \\
\hline Surgical Procedure Group & & & 0.011 \\
\hline General & $539(15.0)$ & $201(14.2)$ & \\
\hline Endocrine & $279(7.8)$ & $131(9.3)$ & \\
\hline Hepatobiliary & $382(10.6)$ & $178(12.6)$ & \\
\hline GI (Upper and Colorectal) & $1162(32.3)$ & $478(33.8)$ & \\
\hline Vascular & $1238(34.4)$ & $426(30.1)$ & \\
\hline \multicolumn{4}{|l|}{ Pre-operative Clinical Characteristics } \\
\hline Pre-op Sepsis & & & 0.005 \\
\hline None & $3293(91.5)$ & $1267(89.6)$ & \\
\hline Sepsis & $145(4.0)$ & $87(6.2)$ & \\
\hline Severe Sepsis & $162(4.5)$ & $60(4.2)$ & \\
\hline Diabetes & $2151(59.8)$ & $1080(76.4)$ & $<0.001$ \\
\hline Sleep Apnea & $729(20.3)$ & $332(23.5)$ & 0.012 \\
\hline Cancer & $156(4.3)$ & $56(4.0)$ & 0.555 \\
\hline $\mathrm{CHF}$ & $87(2.4)$ & $25(1.8)$ & 0.162 \\
\hline COPD & $574(15.9)$ & $216(15.3)$ & 0.559 \\
\hline CAD & $1270(35.3)$ & $452(32.0)$ & 0.026 \\
\hline $\mathrm{DVT} / \mathrm{PE}^{\mathrm{a}}$ & $392(11.4)$ & $150(11.0)$ & 0.711 \\
\hline $\mathrm{ETOH}>2$ drinks/day in the 2 weeks prior to admission & $113(3.1)$ & $32(2.3)$ & 0.096 \\
\hline Tobacco use within 1 year - cigarette & $1011(28.1)$ & $356(25.2)$ & 0.038 \\
\hline Hypertension & $2708(75.2)$ & $1123(79.4)$ & 0.002 \\
\hline Pneumonia & $53(1.5)$ & $27(1.9)$ & 0.266 \\
\hline $\mathrm{HbA} 1 \mathrm{c}^{\mathrm{a}}$ & 6.9 [6.1 to 8.2$]$ & $8.0[6.9$ to 9.6$]$ & $<0.001$ \\
\hline Creatinine $^{a}$ & $0.9[0.7$ to 1.2$]$ & $0.9[0.7$ to 1.3$]$ & 0.313 \\
\hline Ascites & $77(2.1)$ & $21(1.5)$ & 0.132 \\
\hline $10 \%$ Loss of Body Weight 6 Months Before Surgery & $148(4.1)$ & $55(3.9)$ & 0.720 \\
\hline Steroids/Immunosuppressive Meds for chronic condition & $220(6.1)$ & $84(5.9)$ & 0.820 \\
\hline Currently Requires or is on Dialysis & $184(5.1)$ & $39(2.8)$ & $<0.001$ \\
\hline Open Wound With or Without Infection & $502(13.9)$ & $155(11.0)$ & 0.005 \\
\hline Peripheral Vascular Disease & $839(23.3)$ & $330(23.3)$ & 0.981 \\
\hline Ventilator Dependent & $67(1.9)$ & $29(2.1)$ & 0.659 \\
\hline \multicolumn{4}{|l|}{ Intraoperative Characteristics } \\
\hline Surgical Time (Minutes) & 149.0 [95.0 to 237.0$]$ & 185.5 [107.0 to 288.0$]$ & $<0.001$ \\
\hline Insulin Given & $239(6.6)$ & $788(55.7)$ & $<0.001$ \\
\hline \multicolumn{4}{|l|}{ Outcomes } \\
\hline 30 Day Morbidity and Mortality ${ }^{a}$ & $1109(30.9)$ & $538(38.1)$ & $<0.001$ \\
\hline Infectious Complications & $622(17.3)$ & $287(20.3)$ & 0.013 \\
\hline
\end{tabular}

Data are presented as frequency (\%) or median [25th percentile to 75th percentile], as appropriate

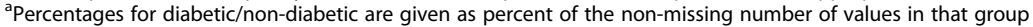


Table 3 Adjusted Primary and Secondary Outcomes

\begin{tabular}{|c|c|c|c|c|c|c|}
\hline & \multicolumn{3}{|c|}{$\begin{array}{l}\text { Primary Outcome: 30-Day Combined Morbidity and } \\
\text { Mortality }\end{array}$} & \multicolumn{3}{|c|}{$\begin{array}{l}\text { Secondary Outcome: 30-Day Infectious } \\
\text { Complications }\end{array}$} \\
\hline & $\begin{array}{l}\text { Adjusted } \\
\text { Odds Ratio }\end{array}$ & $\begin{array}{l}\text { 95\% Confidence } \\
\text { Interval }\end{array}$ & $P$-Value & $\begin{array}{l}\text { Adjusted } \\
\text { Odds Ratio }\end{array}$ & $\begin{array}{l}\text { 95\% Confidence } \\
\text { Interval }\end{array}$ & $P$-Value \\
\hline Age & 1.01 & $1.01,1.02$ & $<0.001$ & 1.01 & $1.00,1.01$ & 0.193 \\
\hline Female Sex & 0.99 & $0.85,1.16$ & 0.903 & 1.01 & $0.85,1.20$ & 0.908 \\
\hline \multicolumn{7}{|l|}{ Race } \\
\hline \multicolumn{7}{|l|}{ White (ref) } \\
\hline American Indian or Alaska Native & 0.48 & $0.10,2.25$ & 0.352 & 0.77 & $0.17,3.57$ & 0.736 \\
\hline Asian & 2.38 & $1.09,5.22$ & 0.030 & 1.59 & $0.65,3.87$ & 0.308 \\
\hline Black or African American & 0.76 & $0.61,0.94$ & 0.013 & 0.87 & $0.68,1.11$ & 0.253 \\
\hline Native Hawaiian or Pacific Islander & 3.04 & $0.07,130.47$ & 0.563 & 4.70 & $0.14,154.14$ & 0.385 \\
\hline Unknown & 0.84 & $0.56,1.27$ & 0.402 & 0.93 & $0.59,1.47$ & 0.761 \\
\hline \multicolumn{7}{|l|}{ WHO BMI Classification } \\
\hline \multicolumn{7}{|l|}{ Normal (ref) } \\
\hline Underweight & 1.16 & $0.68,1.27$ & 0.589 & 1.79 & $1.04,3.10$ & 0.036 \\
\hline Overweight & 0.96 & $0.77,1.67$ & 0.675 & 1.08 & $0.85,1.39$ & 0.525 \\
\hline Obese & 0.98 & $0.80,1.19$ & 0.868 & 1.04 & $0.82,1.31$ & 0.764 \\
\hline \multicolumn{7}{|l|}{ ASA Class } \\
\hline \multicolumn{7}{|l|}{2 (ref) } \\
\hline 1 & $<0.001$ & $<0.001,>999$ & 0.972 & $<0.001$ & $<0.001,>999$ & 0.977 \\
\hline 3 & 1.44 & $1.08,1.91$ & 0.012 & 1.29 & $0.95,1.77$ & 0.108 \\
\hline 4 & 2.41 & $1.75,3.33$ & $<0.001$ & 1.63 & $1.13,2.33$ & 0.008 \\
\hline \multicolumn{7}{|l|}{ Procedure Category } \\
\hline \multicolumn{7}{|l|}{ General (ref) } \\
\hline Endocrine & 1.38 & $0.98,1.93$ & 0.066 & 1.38 & $0.95,2.01$ & 0.091 \\
\hline Gl (Upper or Colorectal) & 1.94 & $1.53,2.46$ & $<0.001$ & 1.85 & $1.41,2.41$ & $<0.001$ \\
\hline Hepatobiliary & 0.67 & $0.48,0.93$ & 0.017 & 0.85 & $0.59,1.23$ & 0.394 \\
\hline Vascular & 0.62 & $0.48,0.81$ & $<0.001$ & 0.52 & $0.39,0.70$ & $<0.001$ \\
\hline Urgent/Emergent Case & 1.90 & $1.61,2.25$ & $<0.001$ & 1.50 & $1.24,1.81$ & $<0.001$ \\
\hline Year 2013 & 1.19 & $0.98,1.45$ & 0.080 & 1.32 & $1.06,1.66$ & 0.015 \\
\hline Year 2014 & 1.02 & $0.84,1.23$ & 0.869 & 1.15 & $0.92,1.43$ & 0.230 \\
\hline Intraop Insulin Administered & 1.20 & $0.96,1.48$ & 0.104 & 1.31 & $1.03,1.67$ & 0.027 \\
\hline Surgical Time (per minute) & 1.004 & $1.003,1.004$ & $<0.001$ & 1.003 & $1.002,1.003$ & $<0.001$ \\
\hline Number of Comorbidities ${ }^{a}$ & 1.16 & $1.11,1.22$ & $<0.001$ & 1.21 & $1.15,1.28$ & $<0.001$ \\
\hline Blood Glucose > 180 mg/dl & 1.05 & $0.86,1.28$ & 0.623 & 0.93 & $0.74,1.16$ & 0.502 \\
\hline
\end{tabular}

${ }^{a}$ Comorbidities include diabetes, ventilator dependence, COPD, pneumonia, ascites, congestive heart failure, hypertension, history of peripheral vascular disease, currently requiring or on dialysis, disseminated cancer, open wound, use of steroids/immunosuppressive medications for chronic condition, $>10 \%$ loss of body weight in the 6 months prior to surgery, alcohol use $>2$ drinks/day in the 2 weeks prior to surgery, presence of sleep apnea, cigarette use within 1 year, presence of sepsis or severe sepsis within $48 \mathrm{~h}$ prior to surgery, history of coronary artery disease, and history of deep vein thrombosis

The World Health Organization (WHO) has published guidelines regarding surgical site infection (SSI) reduction, including recommending intensive glycemic control in the perioperative period for diabetes and non-diabetes patients, although the level of evidence is of low quality [22]. These guidelines have led to initiatives incorporating glycemic control including targeting an intraoperative value of $180 \mathrm{mg} / \mathrm{dl}$ [23]. Two landmark trials that have shaped practice both studied interventions in critical care units. The Leuven trial concluded that tight glucose control (glucose at or below $110 \mathrm{mg} / \mathrm{dL}$ or 6.1 $\mathrm{mmol} / \mathrm{L}$ ) significantly reduced morbidity and mortality in critically ill patients, while NICE SUGAR Study found that intensive glucose control $(81$ to $108 \mathrm{mg} / \mathrm{dL}$ or 4.5 to $6 \mathrm{mmol} / \mathrm{L}$ ) increased mortality compared to a liberal target (less than $180 \mathrm{mg} / \mathrm{dL}$ ) [20, 24]. Neither one of these 
trials included intraoperative data. Overall, there is limited evidence for treatment thresholds in the intraoperative period. A recent meta-analysis demonstrated reduced postoperative mortality with moderate (between 150 and $200 \mathrm{mg} / \mathrm{dL}$ ) vs liberal (greater than $200 \mathrm{mg} / \mathrm{dL}$ ) targets, but no difference in outcome between moderate vs strict control (less than $150 \mathrm{mg} / \mathrm{dL}$ ). However, this analysis was not specific to the intraoperative period [2].

The current data questions the scientific basis of intensive or tight glucose intraoperative protocol for non-cardiac cases. Our sensitivity analysis demonstrated no statistically significant difference in outcomes between glucose less than or greater than 150 $\mathrm{mg} / \mathrm{dL}$ or $8.3 \mathrm{mmol} / \mathrm{L}$. This corroborates findings from the meta-analysis, and strengthens the reproducibility and reliability of our observations. Many anesthesiologists are reluctant to administer insulin to non-diabetics with hyperglycemia intraoperatively due to potentially devastating effects of hypoglycemia under anesthesia. Knowing that moderate vs strict control of hyperglycemia may not be harmful can be reassuring to this group. Post hoc sensitivity analysis of blood glucose $\geq 250$ demonstrating higher morbidity/mortality does reinforce that poorly controlled blood glucose may be harmful, but we did not observe this finding for our secondary outcome of infectious complications.

Hyperglycemia in non-diabetic patients, sometimes known as stress induced hyperglycemia $(\mathrm{SIH})$, is associated with poorer outcomes compared to hyperglycemia in patients with diabetes [25]. In these cases, hyperglycemia can be a response to acute illness or injury. Even though glucose returns to normal after the illness or injury abates, hyperglycemia, including pre-admission glycemic control and admission hyperglycemia, appears to be independently associated with perioperative morbidity [26]. Emerging research has demonstrated that there may be additional factors, such as intraoperative glucose variability, that impact postoperative morbidity [27, 28]. These findings underscore the need for additional research into specific treatment thresholds based on patient comorbidities and physiologic response to surgery [29].

Despite the limitations of this study (described below), our findings support the need for a less strict intraoperative glycemic control. Furthermore, there may be significant opportunities for practice improvement in measurement, treatment and monitoring of intraoperative glucose. Patients with fewer comorbidities, but additional risk due to stress hyperglycemia or glucose variability may need more glucose testing than they are currently obtaining. Additional testing may uncover patients with undiagnosed diabetes and prediabetes [25]. Finally, real- time alerting systems can help providers adhere to standard of care practices during the intraoperative period and reduce the incidence of both hyper and hypoglycemia [15].

\section{Limitations}

We found $~ 5000$ cases (out of almost 93,000 cases) had intraoperative glucose measurements. This was lower than we expected in this large general surgery population. However, we believe this represents the actual care provided from this broad representation of hospital types since the nurse abstractors assigned to the MSQC are specifically trained to obtain the information required by the registry. As one can imagine, there is wide variation in culture and practice patterns across hospitals to perform intraoperative pointof-care testing. However, given the lack of electronic medical records in some hospitals, there is a possibility of missing data due to manual abstraction from paper records. This dataset did not provide access to the specific time intraoperatively that the peak glucose was recorded, nor did we have access to subsequent glucose values to understand results of treatment.

The data on insulin administration suggests that there are patients with hyperglycemia in the perioperative period that this study does not capture. Among the patients with diabetes $(18,207 / 92,751)$ insulin was given to 942 patients, but only 824 of these had a documented intraoperative blood glucose. We think it is likely that these remaining 118 patients who received insulin had high blood glucose values, but this was not captured by our study dataset, perhaps because blood glucose values were only measured preoperatively and not intraoperatively. Future studies could look at a MSQC dataset combined with glucose measurements performed before and after the intraoperative time period to obtain a broader assessment of perioperative glucose management.

Finally, this study is limited by the factors that limit all retrospective designs: confounders, inability to assert causality, and selection bias [30].

\section{Conclusion}

Perioperative glycemic management is an important part of anesthetic care. In our study, we found no statistically significant difference in 30-day combined morbidity and mortality or 30-day infectious complications between patients who had peak glucose levels greater than or less than $180 \mathrm{mg} / \mathrm{dL}$, and conclude that this moderate glycemic target is not associated with poor outcomes in our multicenter sample of general surgery cases.

\section{Abbreviations}

ASA: American Society of Anesthesia; BMI: Body Mass Index; CAD: coronary artery disease; COPD : chronic obstructive pulmonary disease.; Cl: confidence interval; Gl: gastrointestinal; MSQC: Michigan Surgical Quality Collaborative; 
AOR: adjusted odds ratio; SIH: stress induced hyperglycemia; STROBE: Strengthening the Reporting of Observational Studies in Epidemiology; SSI: Surgical Site Infection; WHO: World Health Organization

\section{Acknowledgments}

None.

\section{Authors' contributions}

- NJS: This author helped with hypothesis generation, review of literature, manuscript drafting and revision, and interpretation of data. · AL: This author helped with data acquisition and statistical analysis, manuscript drafting and revision. · SK: This author helped with hypothesis generation, manuscript revision, and interpretation of data. - MJE: This author helped with hypothesis generation, manuscript revision, and interpretation of data. SSK: This author helped with hypothesis generation, review of literature, manuscript drafting, manuscript revision, and interpretation of data. All authors provided Final Approval of manuscript before submission.

\section{Funding}

This work was supported by the Department of Anesthesiology, University of Michigan, Ann Arbor, MI, USA. No external funding was used for this study.

\section{Availability of data and materials}

The datasets generated during and/or analyzed during the current study are available from the corresponding author on reasonable request. The source of this data is the Michigan Surgical Quality Collaborative registry.

\section{Ethics approval and consent to participate}

De-identified MSQC data collection for quality improvement is Institutional Review Board exempt; the current study using a limited data set derived from the MSQC database was approved by the University of Michigan Institutional Review Board review (HUM 00091060).

\section{Consent for publication}

Not applicable.

\section{Competing interests}

None.

\section{Author details}

'Department of Anesthesiology, University of Michigan Medical School, H247 UH, SPC 5048, 1500 East Medical Center Drive, Ann Arbor, Ml 48109-5048, USA. ${ }^{2}$ Department of Surgery, University of Michigan Medical School, Ann Arbor, MI, USA.

\section{Received: 1 October 2019 Accepted: 24 April 2020}

Published online: 07 May 2020

\section{References}

1. Sebranek JJ, Lugli AK, Coursin DB. Glycaemic control in the perioperative period. Br J Anaesth. 2013;111(Suppl 1):i18-34.

2. Sathya B, Davis R, Taveira T, Whitlatch H, Wu WC. Intensity of peri-operative glycemic control and postoperative outcomes in patients with diabetes: a meta-analysis. Diabetes Res Clin Pract. 2013;102:8-15.

3. Alexiewicz JM, Kumar D, Smogorzewski M, Klin M, Massry SG. Polymorphonuclear leukocytes in non-insulin-dependent diabetes mellitus: abnormalities in metabolism and function. Ann Intern Med. 1995;123:919-24.

4. Galindo RJ, Fayfman M, Umpierrez GE. Perioperative Management of Hyperglycemia and Diabetes in cardiac surgery patients. Endocrinol Metab Clin N Am. 2018;47:203-22

5. Esposito K, Nappo F, Marfella R, et al. Inflammatory cytokine concentrations are acutely increased by hyperglycemia in humans: role of oxidative stress. Circulation. 2002;106:2067-72

6. Palermo NE, Gianchandani RY, McDonnell ME, Alexanian SM. Stress hyperglycemia during surgery and anesthesia: pathogenesis and clinical implications. Curr Diab Rep. 2016;16:33.

7. McCowen KC, Malhotra A, Bistrian BR. Stress-induced hyperglycemia. Crit Care Clin. 2001:17:107-24.

8. Doenst T, Wijeysundera D, Karkouti K, et al. Hyperglycemia during cardiopulmonary bypass is an independent risk factor for mortality in patients undergoing cardiac surgery. J Thorac Cardiovasc Surg. 2005;130:1144.
9. Blaha J, Mraz M, Kopecky P, et al. Perioperative tight glucose contro reduces postoperative adverse events in nondiabetic cardiac surgery patients. J Clin Endocrinol Metab. 2015;100:3081-9.

10. Kotagal M, Symons RG, Hirsch IB, et al. Perioperative hyperglycemia and risk of adverse events among patients with and without diabetes. Ann Surg. 2015;261:97-103.

11. Ramos M, Khalpey Z, Lipsitz S, et al. Relationship of perioperative hyperglycemia and postoperative infections in patients who undergo general and vascular surgery. Ann Surg. 2008;248:585-91.

12. Frisch A, Chandra P, Smiley D, et al. Prevalence and clinical outcome of hyperglycemia in the perioperative period in noncardiac surgery. Diabetes Care. 2010;33:1783-8.

13. Shanks AM, Woodrum DT, Kumar SS, Campbell DA Jr, Kheterpal S. Intraoperative hyperglycemia is independently associated with infectious complications after non-cardiac surgery. BMC Anesthesiol. 2018;18:90.

14. Nair BG, Horibe M, Neradilek MB, Newman SF, Peterson GN. The effect of intraoperative blood glucose management on postoperative blood glucose levels in noncardiac surgery patients. Anesth Analg. 2016;122:893-902.

15. Sathishkumar S, Lai M, Picton $P$, et al. Behavioral modification of intraoperative hyperglycemia management with a novel real-time audiovisual monitor. Anesthesiology. 2015;123:29-37.

16. Campbell DA Jr, Kubus JJ, Henke PK, Hutton M, Englesbe MJ. The Michigan surgical quality collaborative: a legacy of Shukri Khuri. Am J Surg. 2009;198: S49-55.

17. Share DA, Campbell DA, Birkmeyer N, et al. How a regional collaborative of hospitals and physicians in Michigan cut costs and improved the quality of care. Health affairs (Project Hope). 2011;30:636-45.

18. Healy MA, Regenbogen $S E$, Kanters $A E$, et al. Surgeon variation in complications with minimally invasive and open colectomy: results from the Michigan surgical quality CollaborativeSurgeon variation in complications with minimally invasive and open ColectomySurgeon variation in complications with minimally invasive and open colectomy. JAMA Surg. 2017:152:860-7.

19. von Elm E, Altman DG, Egger M, Pocock SJ, Gotzsche PC, Vandenbroucke $J P$. The strengthening the reporting of observational studies in epidemiology (STROBE) statement: guidelines for reporting observational studies. J Clin Epidemiol. 2008:61:344-9.

20. van den Berghe $G$, Wouters $P$, Weekers $F$, et al. Intensive insulin therapy in critically ill patients. N Engl J Med. 2001;345:1359-67.

21. Ammori JB, Sigakis M, Englesbe MJ, O'Reilly M, Pelletier SJ. Effect of intraoperative hyperglycemia during liver transplantation. J Surg Res. 2007; 140:227-33.

22. WHO Guidelines Approved by the Guidelines Review Committee. Global Guidelines for the Prevention of Surgical Site Infection. Geneva: World Health Organization Copyright (c) World Health Organization 2016; 2016.

23. Hopkins L, Brown-Broderick J, Hearn J, et al. Implementation of a referral to discharge glycemic control initiative for reduction of surgical site infections in gynecologic oncology patients. Gynecol Oncol. 2017:146:228-33.

24. Investigators N-SS, Finfer S, Chittock DR, et al. Intensive versus conventional glucose control in critically ill patients. N Engl J Med. 2009;360:1283-97.

25. Abdelmalak B, Abdelmalak JB, Knittel J, et al. The prevalence of undiagnosed diabetes in non-cardiac surgery patients, an observational study. Can J Anaesth. 2010;57:1058-64.

26. Kerby JD, Griffin RL, MacLennan P, Rue LW 3rd. Stress-induced hyperglycemia, not diabetic hyperglycemia, is associated with higher mortality in trauma. Ann Surg. 2012;256:446-52.

27. Eslami S, Taherzadeh Z, Schultz MJ, Abu-Hanna A. Glucose variability measures and their effect on mortality: a systematic review. Intensive Care Med. 2011;37:583-93.

28. Wu YC, Ding Z, Wu J, Wang YY, Zhang SC, Wen Y, Dong WY, Zhang QY. Increased glycemic variability associated with a poor 30-day functional outcome in acute intracerebral hemorrhage. J Neurosurg. 2018;129:861-9.

29. Duggan EW, Carlson K, Umpierrez GE. Perioperative hyperglycemia management: an update. Anesthesiology. 2017;126:547-60.

30. Euser AM, Zoccali C, Jager KJ, Dekker FW. Cohort studies: prospective versus retrospective. Nephron Clinical Practice. 2009;113:c214-c7.

\section{Publisher's Note}

Springer Nature remains neutral with regard to jurisdictional claims in published maps and institutional affiliations. 